\title{
SISTEM PENDUKUNG KEPUTUSAN PEMILHAN CALON PERANGKAT DESA TAPIAN NAULI KECAMATAN LINTONG NIHUTA DENGAN METODE SIMPLE ADDITIVE WEIGHTING (SAW)
}

\author{
Sarah Afriani Sihombing, Jijon Raphita Sagala ${ }^{凶}$ \\ Program Studi Teknik Informatika, STMIK Pelita Nusantara, Medan, Indonesia \\ Email: sisagala@gmail.com
}

DOI: https://doi.org/10.46880/jmika.Vol4No2.pp120-125

\begin{abstract}
Village officials who carry out most of the tasks of village heads carried out by village officials are those who assist the Village Head in implementing good governance with village officials who are able to work closely with the village head to advance good human resources. Village officials are important in the village in serving the community. Currently, in Tapian Nauli village, the selection of candidates for the village apparatus is still manual so that services to the community will be hampered. Until now there has not been an effective selection of candidates for village officials for the selection of candidates for the village apparatus Tapian Nauli. Buts Nauli. This system was built using the Additive weighting method so that a simple program that can be done more effectively. Additive weighting simple method one of the methods used in the decision support system with the calculation process by finding the weight value or suitability assessment for each attribute.
\end{abstract}

Keywords: Decision Support System, Simple Additive Weighting, The Village Officials.

\begin{abstract}
ABSTRAK
Perangkat Desa adalah yang melakukan sebagian besar tugas kepala desa yang dikerjakan perangkat desa adalah yang membantu Kepala Desa dalam menjalankan pemerintahan yang baik dengan adanya perangkat desa yang mampu bekerja sama dengan kepala desa untuk memajukan sumber daya manusia yang baik. Perangkat Desa ialah sesuatu hal penting di desa untuk pelayanan terhadap masyarakat. Saat ini di desa Tapian Nauli dalam memilih calon perangkat desa masih dengan cara manual jadi pelayanan kepada masayarakat akan terhambat. Sampai saat ini belum adanya sistem dalam memilih calon perangkat desa yang efektif untuk pemilihan calon perangkat desa Tapian Nauli cara penyeleksian dalam menentukan siapa yang akan lolos dan menduduki posisi jabatan perangkat desa hal tersebut kurang efektif. Penelitian ini bertujuan untuk membantu pihak desa dalam Pemilihan calon perangkat Desa Tapian Nauli. Sistem ini dibangun menggunakan metode SAW agar sistem yang diprogram dapat dilakukan lebih efektif. metode SAW salah satu metode yang digunakan dalam sistem pendukung keputusan dengan proses perhitungnya dengan mencari nilai bobot atau rating kecocokan untuk setiap atribut.
\end{abstract}

Kata Kunci: Sistem Pendukung Keputusan, Simple Additive Weighting, Perangkat Desa.

\section{PENDAHULUAN}

Perangkat Desa adalah yang melakukan sebagian besar tugas kepala desa yang dikerjakan perangkat desa adalah yang membantu pihak Desa menjalankan pemerintahan yang baik. Perangkat Desa yang penting dalam desa, jika tidak adanya perangkat desa maka pelayanan kepada masayarakat akan terhambat. Perangkat Desa memeliliki kedudukan atau tugas masing-masing yang penting dalam mengerjakan tugasnya, Pemerintahan desa berjalan dengan baik jika didapatkan adanya perangkat desa yang mampu bekerja sama dengan kepala desa untuk memajukan sumber daya manusia agar lebih baik. Program untuk meningkatkan SDM dengan adanya suatu organisasi pemerintah desa tidak lepas dari konteks kepemimpinan transformasional dan pembinaan motivasi, serta budaya organisasi pada perangkat desa agar mereka mampu berkreatifitas dan berinovasi dalam menyelesaikan berbagai tugas yang diemban dan kinerjanya.

Permasalahan yang ditemukan pada lokasi penelitian berupa belum adanya penerapan teknologi informasi yang terkomputerisasi untuk pemilihan calon perangkat desa di Desa Tapian Nauli Kecamatan Lintong Nihuta, pihak desa kesulitan dalam penentuan pemilihan calon perangkat desa dan sistem yang sekarang tidak efektif dalam penentuan pemilihan calon perangkat desa. Oleh karena itu, peneliti tertarik 
untuk menerapkan metode Simple Additive Weighting pada sistem pendukung keputusan untuk menentukan pemilihan calon perangkat desa dengan memberi informasi tentang probabilitas nilai kepastian dari pemilihan calon perangkat desa.

Beberapa penelitian yang telah dilakukan dengan metode Simple Additive Weighting diantaranya pada seleksi perangkat desa baru di Kecamatan Mojo, Kabupaten Kediri (Aringga, 2017), penggunaan Simple Additive Weighting untuk penentuan wali kelas berdasarkan prestasi guru (Lumbantoruan \& Simarmata, 2018), penentuan pemberian pinjaman BUMDes dengan Simple Additive Weighting (Utami, Fahmi, \& Sindar, 2019), penerapan Simple Additive Weighting untuk penerima beasiswa (Harianja, 2016) dan pemilihan guru terbaik dengan metode MultiObjective optimization by Ratio Analysis dan Simple Additive Weighting (Manurung, Larosa, Simamora, Gea, Simarmata, \& Situmorang, 2019).

\section{TINJAUAN PUSTAKA}

\section{Sistem Pendukung Keputusan}

Sistem Pendukung Keputusan tidak dimaksudkan untuk mengotomatisasikan pengambilan keputusan, tetapi memberikan perangkat interaktif yang memungkinkan pengambil keputusan untuk melakukan berbagai analisis menggunakan modelmodel yang tersedia (Ernawati, Hidayah, \& Fetrina, 2017). Metode Simple Additive Weighting (SAW) sering juga dikenal dengan istilah metode penjumlahan terbobot. Konsep dasar metode SAW adalah mencari penjumlahan terbobot dari rating kinerja pada setiap alternatif pada semua atribut. Metode SAW membutuhkan proses normalisasi matriks keputusan (X) ke suatu skala yang dapat diperbandingkan dengan semua rating alternatif yang ada MADM itu merupakan suatu metode yang digunakan untuk mencari alternatif optimal dari sejumlah alternatif dengan kriteria tertentu. Metode SAW mengharuskan pembuat keputusan menentukan bobot bagi setiap atribut. Skor total untuk alternatif diperoleh dengan menjumlahkan seluruh hasil perkalian antara rating dan bobot tiap atribut. Rating tiap atribut haruslah bebas dimensi dalam arti telah melewati proses normalisasi matriks sebelumnya (Anna, 2014).

Metode Simple Additive Weighting adalah metode penjumlahan terbobot. Konsep dasar dari metode simple additive weighting adalah mencari penjumlahan terbobot dari rating kinerja pada setiap alternatif pada semua atribut. Metode simple additive weighting membutuhkan proses normalisasi matrik keputusan (X) ke skala yang dapat diperbandingkan dengan semua rating alternative yang ada (Rosmiati \& Hidayatun, 2018).

Adapun langkah-langkah penyelesaian pada metode SAW adalah sebagai berikut:

1. Menentukan alternatif, yaitu $A_{i}$.

2. Menentukan kriteria yang akan dijadikan acuan dalam pengambilan keputusan, yaitu $\mathrm{C}_{\mathrm{j}}$.

3. Memberikan nilai rating kecocokan setiap alternatif pada setiap kriteria.

4. Menentukan bobot preferensi atau tingkat kepentingan (W) setiap kriteria.

$\mathrm{W}=[\mathrm{W} 1, \mathrm{~W} 2, \mathrm{~W} 3, . . \mathrm{WJ}]$.

5. Membuat tabel rating kecocokan dari setiap alternatif pada setiap kriteria.

6. Membuat matrik keputusan yang dibentuk dari table rating kecocokan

$$
\mathrm{X}=\left[\begin{array}{ccc}
r 11 & r 12 \cdots & r i j \\
\vdots & \cdots & \vdots \\
r i 1 & r i 2 \cdots & r i j
\end{array}\right]
$$

7. Melakukan normalisasi matrik keputusan dengan cara menghitung nilai rating kinerja ternomalisasi $\left(\mathrm{r}_{\mathrm{ij}}\right)$ dari alternatif $\mathrm{A}_{\mathrm{i}}$ pada kriteria $\mathrm{Cj}$. Formula untuk melakukan normalisasi tersebut adalah perhitungan normalisasi berdasarkan cost dan benefit.

8. Hasil dari nilai rating kinerja ternomalisasi (rij) membentuk matrik ternormalisasi (R)

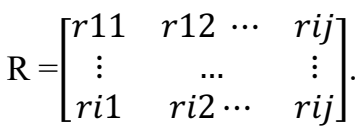

Hasil akhir nilai preferensi $\left(\mathrm{V}_{\mathrm{i}}\right)$ diperoleh dari penjumlahan dari perkalian elemen baris matriks ternormalisasi (R) dengan bobot preferensi (W) yang bersesuaian eleman kolom matrik (W). niali preferensi untuk setiap alternatif.(Vi) diberikan sebagai :

$$
\mathrm{V}_{\mathrm{i}}=\sum_{j=1}^{n} W j R i j
$$

Nilai preferensi untuk setiap alternatif diperoleh dengan menjumlahan hasil perkalian antara rating kinerja ternormalisasi dengan bobot setiap kriteria. Dimana :

$\mathrm{V}_{\mathrm{i}}=$ Nilai akhir dari alternati

$\mathrm{Wj}=$ Bobot yang telah ditentukan

$\mathrm{R}_{\mathrm{ij}}=$ Normalisasi matriks

Hasil perhitungan nilai Vi yang lebih besar mengindentifikasi bahwa alternatif Ai merupakan alternatif terbaik.

\section{Perangkat Desa}

Perangkat desa bertugas membantu kepala desa dalam pelaksanaan tugas menyelenggarakan 
pemerintahan desa, melaksanakan pembangunan desa, pembinaan kemasyarakatan desa, dan pemberdayaan masyarakat desa. Perangkat desa diangkat oleh kepala desa setelah dikonsultasikan dengan camat atas nama bupati/walikota. Dalam melaksanakan tugas dan wewenangnya, perangkat desa bertanggung jawab kepada kepala desa (Undang-Undang Republik Indonesia tentang Desa).

\section{METODE PENELITIAN}

Kerangka kerja penelitian dimana kerangka kerja penelitian ini yang digunakan seperti terlihat pada gambar 3.1 berikut ini:

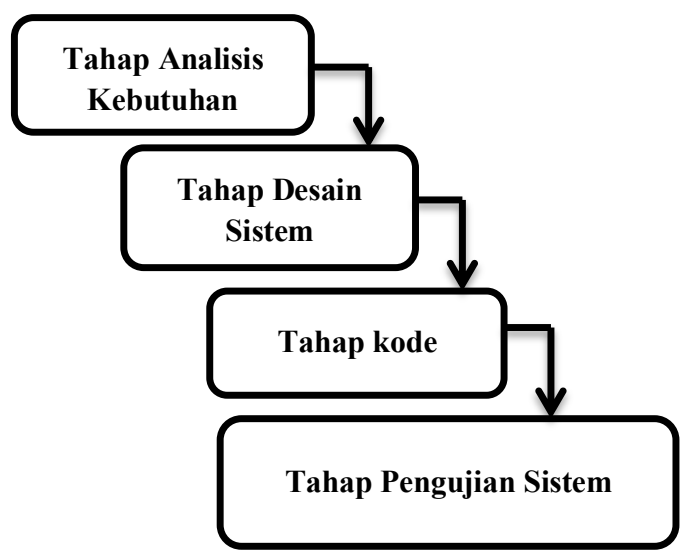

Gambar 1. Kerangka Kerja Penelitian

\section{ANALISIS DAN PERANCANGAN}

Analisis adalah usaha mengamati secara akurat pada sebuah hal ataupun benda dan menguraikan komponen-komponen yang membentuknya untuk menyusun komponen yang telah di uraikan untuk dikaji selanjutnya. Tahap analisa merupakan awal untuk mengidentifikasi serta memecahkan masalah karena proses analisa yang akurat dapat menyebabkan hasil pengembangan sistem, sistem yang akan dibangun tidak lepas dari data-data pemilihan Perangkat Desa yang memanfaatkan metode (SAW) dalam proses pengambilan keputusan. Analisa Metode (SAW) Metode SAW bisa dapat diartikan sebagai metode pembobotan sederhana atau penjumlahan terbobot dengan menyelesaikan masalah dengan sistem pendukung keputusan.

Tabel 1. Data Kriteria

\begin{tabular}{|l|l|l|}
\hline Kriteria & \multicolumn{1}{|c|}{ Sub kriteria } & Keterangan \\
\hline C1 & $\begin{array}{l}\text { Warga desa yang memiliki } \\
\text { status kependudukan didesa }\end{array}$ & Benefit \\
& yang bersangkutan, baik & \\
& bertempat tinggal di desa & \\
& dan / atau diluar desa. & \\
\hline C2 & $\begin{array}{l}\text { Memegang teguh dan } \\
\text { mengamalkan pancasila, }\end{array}$ & \\
& melaksanakan undang- & \\
& &
\end{tabular}

\begin{tabular}{|c|c|c|}
\hline & $\begin{array}{lr}\text { undang Dasar } & \text { Negara } \\
\text { Republik Indonesia } & \text { Tahun } \\
1945, & \text { serta } \\
\text { mempertahankan } & \text { dan } \\
\text { memelihara ketuhanan } \\
\text { Negara Keastuan republik } \\
\text { Indonesia dan Bhinneka } \\
\text { Tunggal Ika. }\end{array}$ & \\
\hline $\mathrm{C} 3$ & $\begin{array}{l}\text { Berpendidikan paling } \\
\text { rendah sekolah menengah } \\
\text { umum atau yang sederajat }\end{array}$ & Benefit \\
\hline $\mathrm{C} 4$ & $\begin{array}{l}\text { Berusia paling rendah } 20 \\
\text { (Dua puluh) tahun dan } \\
\text { paling tinggi } 42 \text { (Empat } \\
\text { puluh dua) tahun pada saat } \\
\text { pendaftaran. }\end{array}$ & Cost \\
\hline $\mathrm{C} 5$ & $\begin{array}{l}\text { Tidak pernah dijatuhi } \\
\text { pidana penjara berdasarkan } \\
\text { putusan pengadilan yang } \\
\text { telah mempunyai kekuatan } \\
\text { hukum tetap kerena } \\
\text { melakukan tindak pidana } \\
\text { yang diancam dengan } \\
\text { pidana penjara paling } \\
\text { singkat } 5 \text { (lima) tahun. }\end{array}$ & Benefit \\
\hline C6 & Berkelakuan baik & Benefit \\
\hline $\mathrm{C} 7$ & $\begin{array}{l}\text { Mempunyai kemampuan } \\
\text { untuk mengoperasikan } \\
\text { komputer yang mendukung } \\
\text { kelancaran pelaksanaan } \\
\text { tugas. }\end{array}$ & Benefit \\
\hline $\mathrm{C} 8$ & $\begin{array}{l}\text { Mempunyai pemahaman } \\
\text { tentang kehidupan sosial } \\
\text { budaya setempat. }\end{array}$ & Benefit \\
\hline
\end{tabular}

Sumber: (Desa Tapian Nauli)

Tabel 2. Nilai Bobot

\begin{tabular}{|c|c|}
\hline Nilai Bobot & Keterangan \\
\hline 0 & Sangat Rendah \\
\hline 0,20 & Rendah \\
\hline 0,40 & Sedang \\
\hline 0,60 & Cukup \\
\hline 0,80 & Baik \\
\hline 1,00 & Sangat Baik \\
\hline
\end{tabular}

Bobot preferensi atau tingkat kepentingan $\mathrm{W}=[1.00 ; 0.60 ; 0.80 ; 0,80 ; 1.00 ; 0.80 ; 1.00 ; 0.80]$

Dimana alternative calon perangkat desa:

- Mekaria Panggabean,

- Erniance Siregar,

- Denny Fransiska Sihombing,

Dimana jabatan yang dilamar:

- Kepala seksi kesejahteraan dan pelayaanan. 
Menormalisasi matriks X menjadi matriks R

$X=\left[\begin{array}{llllllll}1.00 & 0.60 & 0.80 & 0.80 & 1.00 & 0.80 & 0.80 & 1.00 \\ 0.20 & 0.60 & 0.80 & 0.80 & 1.00 & 0.60 & 0.60 & 0.80 \\ 1.00 & 0.60 & 0.60 & 0.80 & 1.00 & 0.60 & 0.60 & 0.80\end{array}\right]$

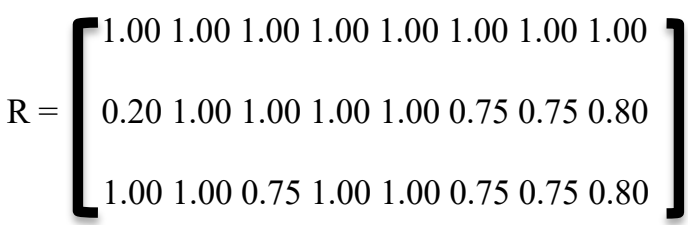

Hasil perhitungan nilai $\mathrm{Vi}$ yang lebih besar mengindentifikasi bahwa alternatif $\mathrm{Ai}$ merupakan alternatif terbaik.

$$
\begin{aligned}
& V_{1}=(1.00 \times 1.00)+(0.60 \times 1.0+(0.80 \times 1.0+ \\
& (0.80 \times 1.00)+(1.00 \times 1.00)+ \\
& (0.80 \times 1.00)+\quad(1.00 \times 1.00)+ \\
& (0.80 \times 1.00) \\
& =1.00+0.60+0.80+0.80+1.00+0.80 \\
& +1.00+0.80 \\
& =6.80 \\
& V_{2}=(1.00 \times 0.20)+(0.60 \times 1.00)+(0.80 \times 1.00)+ \\
& (0.80 \times 1.00)+(1.00 \times 1.00)+ \\
& (0.80 \times 0.75)+(1.00 \times 0.75)+(0.80 \times 0.80) \\
& =0.20+0.60+0.80+0.80+1.00+0.60 \\
& +0.75+0.64 \\
& =5.39 \\
& V_{3}=(1.00 \times 1.00)+(0.60 \times 1.00)+(0.80 \times 0.75) \\
& +(0.80 \times 1.00)+(1.00 \times 1.00) \\
& +(0.80 \times 0.75)+(1.00 \times 0.75) \\
& +(0.80 \times 0.80) \\
& =1.00+0.60+0.60+0.80+1.00+0.60 \\
& +0.75+0.64 \\
& =5.99
\end{aligned}
$$

Hasil Perhitungan

$\mathrm{A} 1=6.80$

$\mathrm{A} 2=5.39$

A $3=5.99$

Tabel 3. Hasil Perangkingan

\begin{tabular}{|c|c|c|}
\hline Rangking & Alternatif & $\mathbf{V}_{\mathbf{i}}$ \\
\hline 1 & $\mathrm{~A}_{1}$ & 6.80 \\
\hline 2 & $\mathrm{~A}_{3}$ & 5.99 \\
\hline 3 & $\mathrm{~A}_{2}$ & 5,39 \\
\hline
\end{tabular}

Dari perangkinan diatas namun calon perangkat desa atu kandidat yang diajukan jika hasil nilai tertinggi. Hasil seleksi menunjukkan bahwa Alternatif A1 memiliki nilai $\mathrm{V}$ yang tertinggi yaitu V1 = 6.80 maka alternative A1 yang terpilih menjadi kandidat calon perangkat Desa kepala seksi kesejahteraan dan pelayanan di Desa Tapian Nauli.

\section{IMPLEMENTASI SISTEM}

Implementasi untuk mempersentasikan hasil program pada penelitian yang merupakan proses penerapan metode SAW yang dirancang menggunakan berbasis web dan menguji program web apakah berjalan dengan baik. Hasil implementasi pada halaman login tampilan awal halaman login adalah seperti user, admin harus memasukan username dan password untuk masuk ke halaman admin, seperti ditampilkan pada gambar berikut.

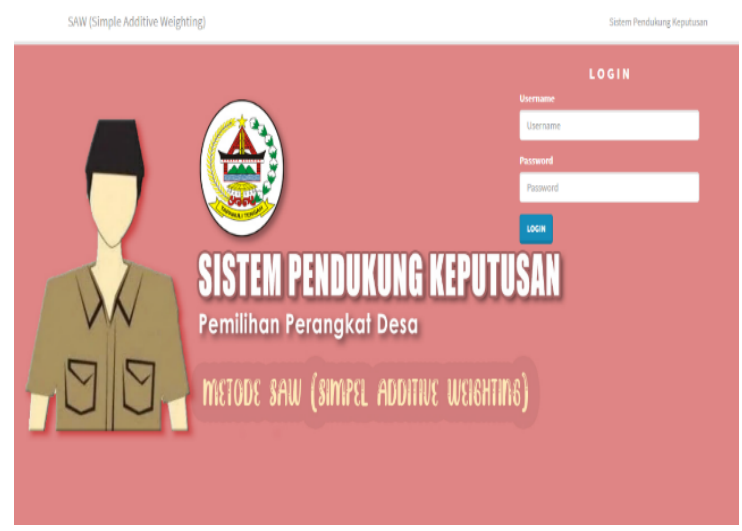

Gambar 2. Halaman Login

Pada halaman utama terdapat beberapa menu yaitu home, nilai, kriteria, alternatif, rangking, laporan dan menu nilai preferensi, kriteria- kriteria, namanama calon perangkat desa, seperti ditampilkan pada gambar berikut.

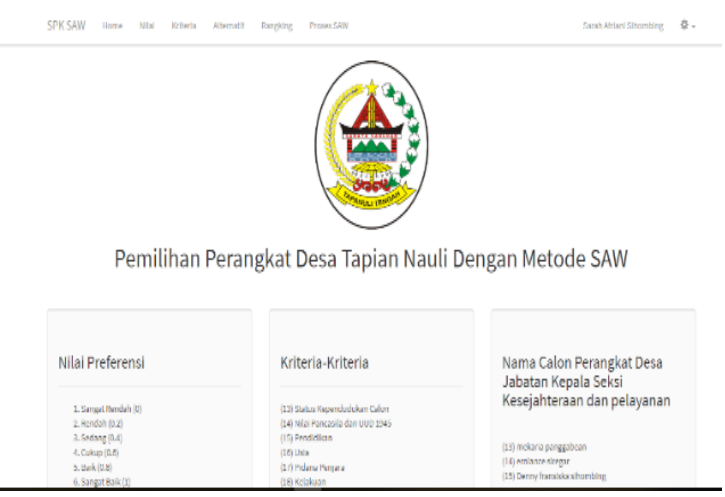

Gambar 3. Halaman Utama

Pada menu data kriteria merupakan menambah dan menginput data kriteria dan 
menetukan tipe kriteria (benefit dan cost) dan bobot kriteria, seperti ditampilkan pada gambar berikut.

\begin{tabular}{l} 
Tambah Kriteria \\
Nama Kriteria \\
\hline Tipe Kriteria \\
\hline Benefit \\
Bobot Kriteria \\
\hline 0 SIMPAN KEMBAL \\
\hline
\end{tabular}

Gambar 4. Halaman Data Kriteria

Pada halaman alternative, disini admin dapat menambah, atau menghapus nama, seperti ditampilkan pada gambar berikut.

\section{Tambah Alternatif}

Nama Alternatif

\section{SIMPAN KEMBALI}

Gambar 5. Halaman Alternatif

Pada halaman menambah rangking ini terdapat beberapa menu yaitu menambah data dengan memilih alternatif, kriteria, dan nilai, seperti ditampilkan pada gambar berikut.

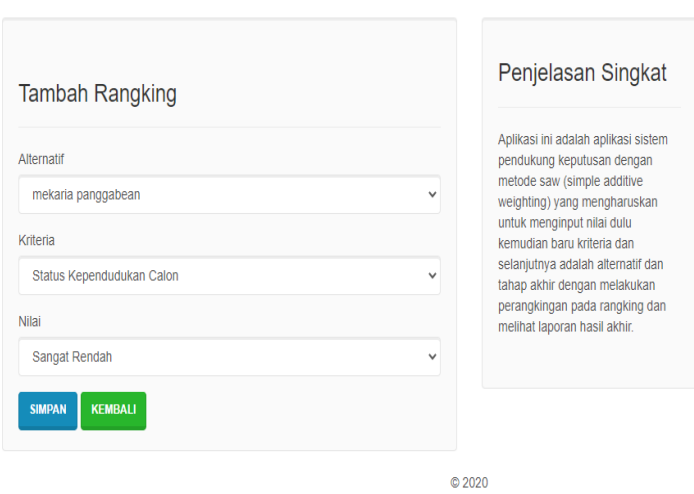

Gambar 6. Tambah Data

Pada menu proses SWA berisi data calon perangkat desa dengan nilai tertinggi bedasarkan perhitungan SAW yang sesuai dengan bobot kriteria yang telah ditentukan dan bisa di cetak berdasarkan data kriteria atau rating kecocokan dari alternatif calon perangkat desa, hasil normalisasi keputusan, hasil akhir, hasil perangkingan dan laporan, seperti yang ditampilkan pada Gambar 7 - 11 berikut.

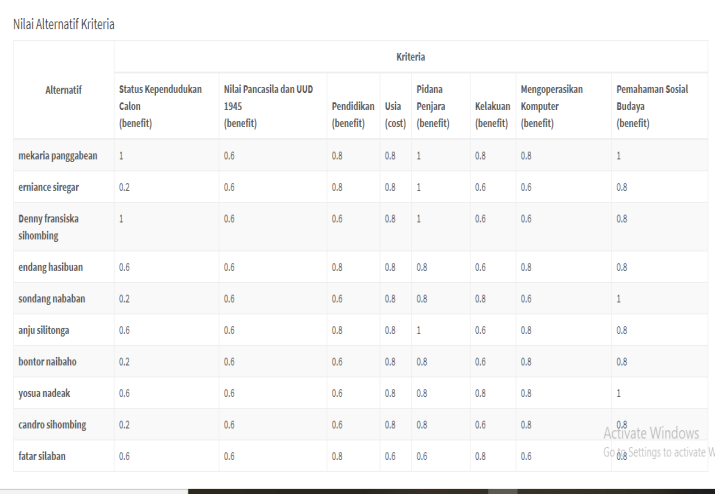

Gambar 7. Tampilan Nilai Alternatif Kriteria

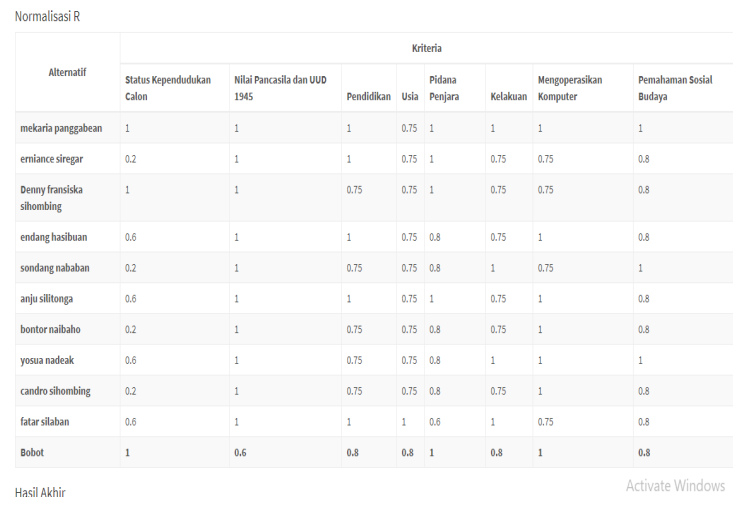

Gambar 8. Tampilan Normalisasi

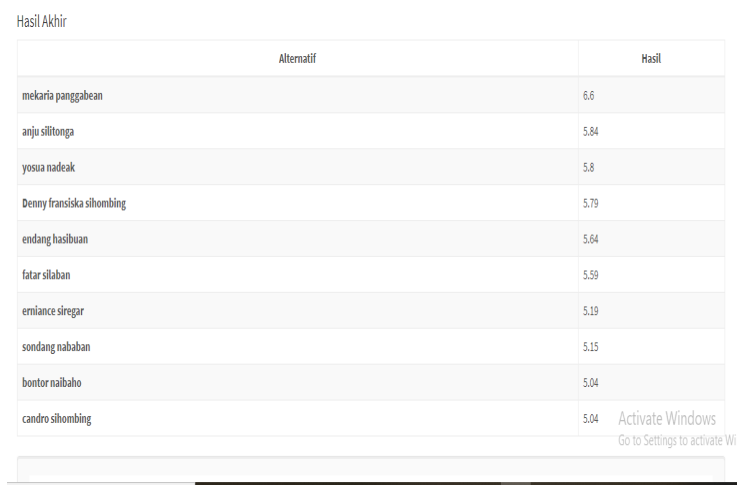

Gambar 9. Tampilan Hasil perangkingan 


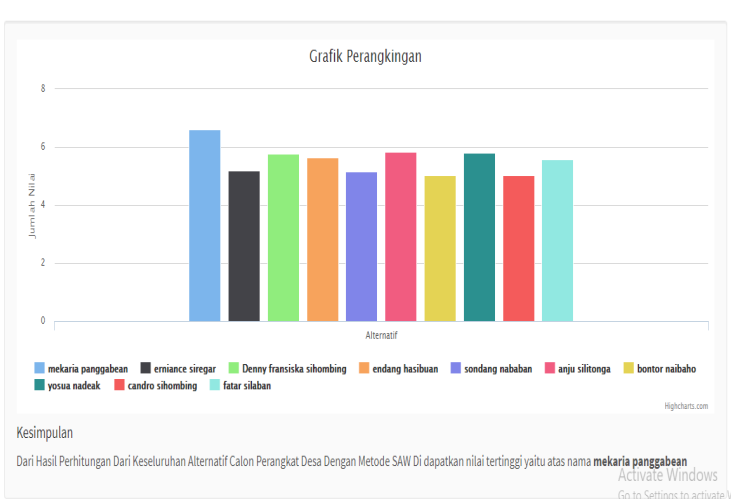

Gambar 10. Grafik Perangkingan dan Kesimpulan

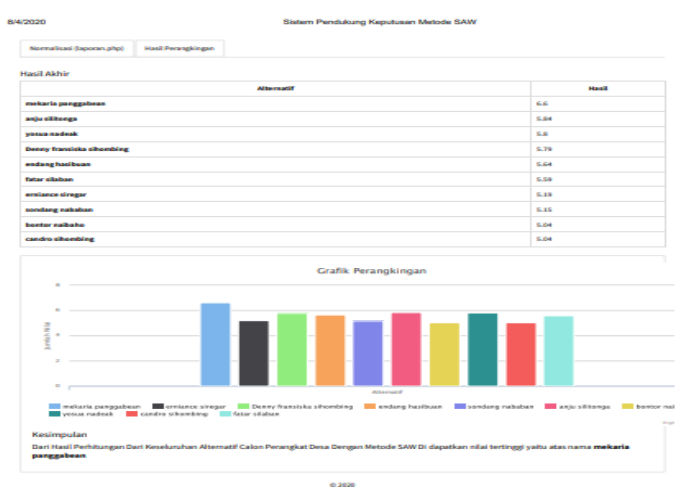

Gambar 11. Tampilan Cetak Laporan

\section{KESIMPULAN}

Dengan adanya pengembangan yang telah dilakukan selama proses analisis sebelumnya dan perancangan hingga implementasi sistem pendukung keputusan maka dapat diambil kesimpulan bahwa sistem pendukung keputusan untuk memilih calon perangkat desa yang baru di Tapian Nauli Kecamatan Lintong Nihuta menggunakan metode SAW terkomputerisasi dan pengujian hasil calon perangkat desa akan lebih mudah dapat diketahui dan membantu pihak desa dalam meyelesaikan tugas secara efektif dan efesien.

\section{DAFTAR PUSTAKA}

Anna, A. P. (2014). Metode Simple Additive Weighting (SAW) . Retrieved Januari 2020, from https;//aeroyid.wordprees.com/

Aringga, R. D. (2017). Sistem Pendukung Keputusan Menggunakan Metode Simple Additive Weighting Dalam Pengolahan Seleksi Perangkat Desa Baru (Studi Kasus: Kecamatan Mojo Kabupaten Kediri). JATI (Jurnal Mahasiswa Teknik Informatika), 1 (1), 283-289.
Kenaikan Jabatan Pegawai Dengan Metode Profile Matching (Studi Kasus: Kementerian Agama Kantor Wilayah DKI Jakarta). Studia Informatika: Jurnal Sistem Informasi, 10 (2), 127-134.

Harianja, E. J. (2016). Penentuan Penerima Beasiswa dengan Format Preferensi Menggunakan Metode Simple Additive Weighting (SAW). Jurnal METHODIKA, 2 (2), 189-192.

Lumbantoruan, G., \& Simarmata, E. R. (2018). Sistem Pendukung Keputusan Penentuan Wali Kelas berdasarkan Prestasi Guru dengan Metode Simple Additive Weighting (Studi Kasus SMK Brigjend Katamso Medan). Pelita Informatika: Informasi dan Informatika, 7 (1), 231-236.

Manurung, S. V., Larosa, F. G., Simamora, I. M., Gea, A., Simarmata, E. R., \& Situmorang, A. (2019). Decision Support System of Best Teacher Selection using Method MOORA and SAW. 2019 International Conference of Computer Science and Information Technology (ICoSNIKOM), (pp. 1-6). IEEE.

Rosmiati, M., \& Hidayatun, N. (2018). Implementasi Metode Simple Additive Weighting Dalam Menentukan Status Gizi Balita Berbasis Web. PARADIGMA, XX(2), 113-122.

Undang-Undang Republik Indonesia tentang Desa. DPR \& Presiden RI.

Utami, N. P., Fahmi, H., \& Sindar, A. (2019). SPK Penentuan Pemberian Pinjaman Kepada Anggota BUMDes Dengan Metode Simple Additive Weighting. SINTECH Journal, 2 (2), 124-130.

Ernawati, Hidayah, N. A., \& Fetrina, E. (2017).

Rancang Bangun Sistem Pendukung Keputusan 